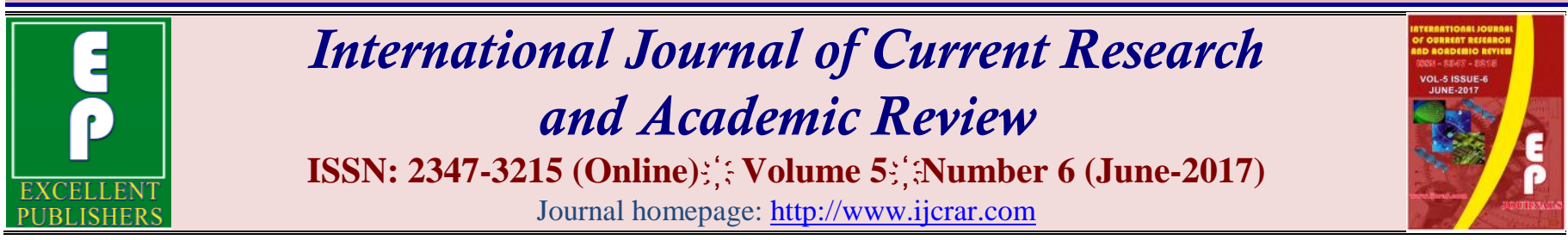

doi: https://doi.org/10.20546/ijcrar.2017.506.006

\title{
Development of Mycorrhizosphere Using Sorghum bicolor for Rhizosphere Biormediation
}

\author{
Jyoti Fulekar, Bhawana Pathak and M.H. Fulekar*
}

School of Environment and Sustainable Development, Central University of Gujarat, Sector 30, Gandhinagar 382030, India

*Corresponding author

\section{Abstract}

The research study evaluates the potential of Sorghum bicolor for development of mycorrhizal soil. The development of soil based mycorrhizal inoculum using sorghum bicolor was carried out under controlled greenhouse conditions. The experiment was carried out for a period of two and half months. The physico-chemical parameters and mycorrhizal characterization such as root colonization and spore count was carried out at regular interval. Significant increase in spore count was observed during the development of mycorrhizal soil. The Sorghum bicolor grown in mycorrhizal soil had higher root colonization (\%) as compare to control soil. The spore count was found to be increasing from 16 of $100 \mathrm{~g} \mathrm{~g}^{-1}$ to $526100 \mathrm{~g}^{-1}$ and root colonization from $3 \%$ to $80 \%$ of mycorrhizal soil when compared to control soil. Root colonization in the mycorrhizal soil was positively correlated $(\mathrm{P}<0.001)$ with spore count. The response of mycorrhizal characteristics such as root colonization and spore count to physicchemical parameters such as $\mathrm{pH}$, carbon content, moisture, phosphorous and nitrogen was analysed. Soil moisture had a positive influence on root colonization and spore count, while phosphorous was negatively correlated with root colonization and spore count. Mycorrhizal soil showed a significant positive correlation between root colonization and spore count with nitrogen and organic carbon. Thus development of mycorrhizal soil induces series of changes in soil physico-chemical characteristics and nutrient availability that may determine outcome of rhizosphere bioremediation. The development of effective mycorrhizosphere in the present research study can provide a suitable environment for enhanced degradation of organic pollutants in soil.
\end{abstract}

\section{Article Info}

Accepted: 05 June 2017

Available Online: 20 June 2017

\section{Keywords}

Mycorrhizosphere,

Sorghum bicolor,

Rhizosphere

bioremediation,

Mycorrhizal soil.

\section{Introduction}

The mutualistic symbiotic association of fungi and plant is known as mycorrhiza (kirk et al., 2001) which provides effective rhizosphere for degradation of recalcitrant organic contaminants. Glomeromycotan fungi produce mycorrhizal association are known as arbuscular mycorrhizas or vesicular arbuscular mycorrhizas. VAM fungi are vital components of ecosystem for maintenance of soil structure and revegetation of degraded lands (Caravaca et al., 2005). The physiology of the host plants is influenced by VAM thus making them resistant to drought, pathogens, soil pollution, salinity and other environmental stress factors. VAM also influences root colonization of the host plant that alters microbial equilibrium in the mycorrhizosphere 
by inducing changes in root exudation pattern. VAM are known to improve soil mineral nutrients thereby improving the growth and health of the plants. Vesicular arbuscular mycorrhizal have been described for nutrient such as phosphorous which has restricted mobility in soil. It is observed by Azcon et al., (2003) that VAM colonized plants accumulate and absorb more phosphorous compared to plants that are not colonized, grown in soil that have low phosphorous. Phosphorous transfer and uptake is also affected when the supply of photosynthate to fungi decreased. The supply of phosphorous to the plant varies with VAM species. In some cases arbuscular mycorrhizae are poor symbionts providing little phosphorous while taking relatively high amounts of carbon. Not only the uptake of phosphorous is enhanced but also enhance uptake of macro and micronutrients $\mathrm{Ca}, \mathrm{Cu}, \mathrm{Mg}, \mathrm{S}, \mathrm{Fe}, \mathrm{N}, \mathrm{Zn}$ by VAM colonization of plant roots (Allen et al., 2003). VAM as it can act as bioprotectants, biofertilizer and biodegraders can alter plant productivity (Khan, 2006). Mycorrhiza not only improves the structure of soil by providing the plants with water and mineral compounds but also act as filters, reducing toxicity to the plants by blocking hazardous compounds within their mycelium. Khan (2006) reported that Vesicular arbuscular mycorrhiza modifies the abundance and quality of microflora in the rhizosphere which enhance bioremediation of contaminants present in the soil by altering overall rhizospheric microbial activity. Rhizosphere Bioremediation encourages degradation of organic contaminants in the soil by increasing bacterial population, soil organic carbon and mycorrhizal fungi (Schnoor, 1997).The mycorrhizospheric microflora in symbiotic association with mycorrhizal fungi can degrade organic contaminants. Several research studies carried out show that persistent organic pollutants like polycyclic aromatic hydrocarbons, aromatic hydrocarbons and hexachlorocyclohexane can be degraded or transform into less toxic form, directly or indirectly in the mycorrhizosphere (Huang et al., 2006; Sainz et al., 2006; Volante et al., 2005). Since the development of the mycorrhizosphere by inoculation of mycorhiza has shown tolerance to toxic compounds, and also modifies the quality and abundance rhizo-microbial population responsible for biodegradation of contaminated soil, hence said to optimize the success of phytoremediation. The objective of this study is to develop reliable soil based mycorrhizal inoculum for effective Rhizosphere Bioremediation of hazardous compound and to study the influence of mycorrhiza on soil physico-chemical parameters during the development of mycorrhizosphere.

\section{Material and Methods}

\section{Test plant, soil sampling and characterization}

Sorghum bicolor commonly called as sorghum was selected for development of mycorrhizal soil at laboratory scale. The sorghum seed were procured from Ratanshi Agro-hortitech (Byculla, Mumbai). Prior to their use in the experiment, the seeds were surface-sterilized for 5 mins with $0.1 \%$ mercuric chloride and subsequently washed several times with distilled water to avoid fungal contamination. The washed seeds were placed in the Petri dishes containing moist filter paper and germinated for a period of three days in dark. The germinated seeds were used for the development of mycorrhizal innoculum. The soil used for the development of mycorrhizal soil, was collected along the banks of Surya River palghar from a depth of $0-15 \mathrm{~cm}$. The soil was then air dried and screened through $2 \mathrm{~mm}$ stainless steel and stored at 27-30 C. The soil was mixed vigorously for $20 \mathrm{mins}$ in deionized water and physico-chemical parameters viz. $\mathrm{pH}$, moisture, organic carbon, phosphorus, was analyzed using Standard methods.

\section{Experimental design}

A greenhouse experiment was set up for the development of mycorrhizal soil using pot culture technique under controlled environmental condition with the help of starter inoculum (VAM) in the form of mixture of soil, spores, root fragments and external mycelium procured from microbiology department IARI, New Delhi. The experiment was carried out in $5 \mathrm{~kg}$ capacity pots perforated at the base. Perforations were made at the bases for better aeration and drainage of water. The mixture of soil-sand $(3: 1)$ was used for growing plants to provide homogeneity and porosity of the soil. One third of the tray was inoculated with the starter culture of mycorrhiza with sand:soil mixture. Fifty surface sterilized sorghum seeds were then sown in each tray and their growth was monitored for $2 \frac{1}{2}$ months. The plants were watered and provided with Hogland solution to devoid of phosphorous. Approximately $10 \mathrm{ml}$ of Hogland solution was provided per pot, after 15days. Five perforated pots were placed in a greenhouse with natural sunlight at temperatures of $27-28^{\circ} \mathrm{C}$ during the day and $24-26^{\circ} \mathrm{C}$ during the night. The development of mycorrhiza (mycorrhizal properties) was measured for physico-chemical changes occurring in soil by sampling the rhizospheric soil and harvesting the plant roots at the consistent intervals of 15 days for the total period of 75 days. The physico-chemical parameters of 
mycorhizospheric soil were carried out at regular interval. The collected soil was dried at $105^{\circ} \mathrm{C}$ for water content determination. This soil was then analysed for $\mathrm{pH}$, total nitrogen and total phosphorous content. The spore count and \% colonization by mycorrhizal fungi was also carried out. Sorghum being a fibrous root grass found to grow well for the period of $2 \frac{1}{2}$ months under the green house condition and provided huge network of fine roots inhabiting the soil. After two and half month's incubation, pots were left without watering for a month allowing soil to dry. Almost one third of soil occupied by dense mass of roots in the tray would contain roots colonized with AMF and mycorrhizal spores. Further, roots of the plants were chopped and mixed in the same soil, and stored in the cool dry place $\left(22-25^{\circ} \mathrm{C}\right)$ in polythene bags as 'soil based mycorrhizal inoculum'.

\section{Soil sampling and analysis}

The soil samples from the experimental set up was collected at regular interval in order to determine soil $\mathrm{pH}, \mathrm{N}, \mathrm{OC}, \mathrm{P}$ and moisture content in the rhizospheric soil. The soil samples collected from the triplicate set up were preserved in the plastic bags, secured, labelled and analysed for soil $\mathrm{pH}$ on 1:2.5, soil:water suspension method. Organic carbon was analyzed was analyzed using the Walkley-Black method (Jackson, 1973), total nitrogen content by the Kjeldahl method (Bremmer and Mulvaney, 1982) and available $\mathrm{P}$ determined using the Olson method (Dick and Tatabai,1997).

\section{Mycorrhizal colonization and spore count enumeration}

The fine roots collected at suitable interval where washed under the tap water carefully, until the soil adjacent to roots was completely removed. The fine root samples were then preserved in a plastic jar containing $97 \%$ of ethanol until they were ready for processing. The spores from the soil were separated by wet sieving method (Gerdemann and Nicholson, 1963). The spores from the $25 \mathrm{gm}$ of soil were counted under $10 \mathrm{x}$ magnification of dissecting microscope. The root colonization was identified according to Philips and Hayman, 1970. The roots were washed to remove ethanol and cut into $1-2 \mathrm{~cm}$ in length, put into a beaker containing $10 \% \mathrm{KOH}$ for $24 \mathrm{~h}$, followed by $10 \% \mathrm{H}_{2} \mathrm{O}_{2}$ for $1 \mathrm{~h}$. The roots were then acidified for 15 min with $5 \mathrm{~N}$ HCL and stained with trypan blue in lactophenol. Then selected 20 subsamples of roots were prepared on slide length wise. The proportional root colonization by AMF estimated using the magnified intersection method with hairline graticule inserted into an eyepiece acted as the line of intersection with each root at 400x-magnification power under the compound microscope. From 100 or more intersections of each root sample the percentage of root length colonization was calculated.

\section{Statistical analysis}

The difference between spore count and root colonization during development of mycorrhizal soil and control was analysed using linear regression analysis (Zar, 1984). The relationship between physico-chemical parameters, spore count and on root colonization was analysed using Pearson correlation.

\section{Results and Discussion}

Soil physic-chemical properties of developed mycorrhizal soil had better $\mathrm{pH}, \mathrm{OC}$, Nitrogen than in the collected alluvial soil. The soil physico-chemical properties during the development of mycorrhizal soil were found to be increasing (Table 1). The mean $\mathrm{pH}$ of the mycorrhizal soil lies between $6.3 \pm 0.3$ to $7.4 \pm 0.6$ which have been characterized as neutral (Fig. 1). The organic carbon of the developed mycorrhizal soil was found to be higher $(228 \pm 10.62)$ than the organic carbon in the collected soil (Table 1). Soil moisture was maintained between $40.3 \pm 2.8$ to $46.4 \pm 3.2$ (Fig. 2) and was positively correlated with spore count and root colonization. Redhead, 1975 reported that Vesicular arbuscular mycorrhiza are sensitive to moisture content of the soil and optimum moisture is required for VAM sporulation and infection. The phosphorous content did not vary much during development of mycorrhizal soil which was found to be lower (Fig. 3). Unlike phosphorous, significant increase in the nitrogen content of the soil was observed from 5.7 $\pm 0.08-8.3 \pm 1.4$ (Fig. 1).

The root colonization was significantly correlated with $\mathrm{pH}(\mathrm{P}<0.05)$ while spore count insignificantly correlated with $\mathrm{pH}$. The response of Vesicular arbuscular mycorrhizal fungi to $\mathrm{pH}$ of the soil may depend on the strains and species constituting the indigenous VAM flora (Robson and Abbott, 1989). Alkaline to netural soil has been reported by early workers to favour the predominance of Glomus species (Mosse et al., 1981). Nitrogen showed positive significant correlation with root colonization $(\mathrm{P}<0.05)$ and spore count $(\mathrm{P}<0.01)$. The mycorrhizal formation if influenced by nitrogen and functions mainly through the changes in the $\mathrm{pH}$ of the soil. 
Table.1 Physico-chemical characterization of collected soil sample and developed mycorrhizal soil

\begin{tabular}{lll}
\hline Parameters & Alluvial Soil & Mycorrhizal soil \\
\hline $\mathrm{pH}$ & $6.2 \pm 0.5$ & \\
Moisture content $(\%)$ & $34 \pm 2.4$ & $7.4 \pm 0.6$ \\
Organic carbon $(\mathrm{gm} / \mathrm{kg})$ & $63 \pm 3.4$ & $228 \pm 3.2$ \\
Total Nitrogen $(\mathrm{gm} / \mathrm{kg})$ & $5.2 \pm 0.07$ & $8.3 \pm 1.4$ \\
Phosphorous $(\mathrm{gm} / \mathrm{kg})$ & $0.65 \pm 0.01$ & $0.66 \pm 0.03$ \\
Spore count $(\mathrm{per} 100$ gms of soil) & 12 & 526 \\
Root colonization $(\%)$ & - & 80
\end{tabular}

Fig.1 and 2 soil pH and Nitrogen during development of mycorrhizal soil and Soil moisture during development of mycorrhizal soil

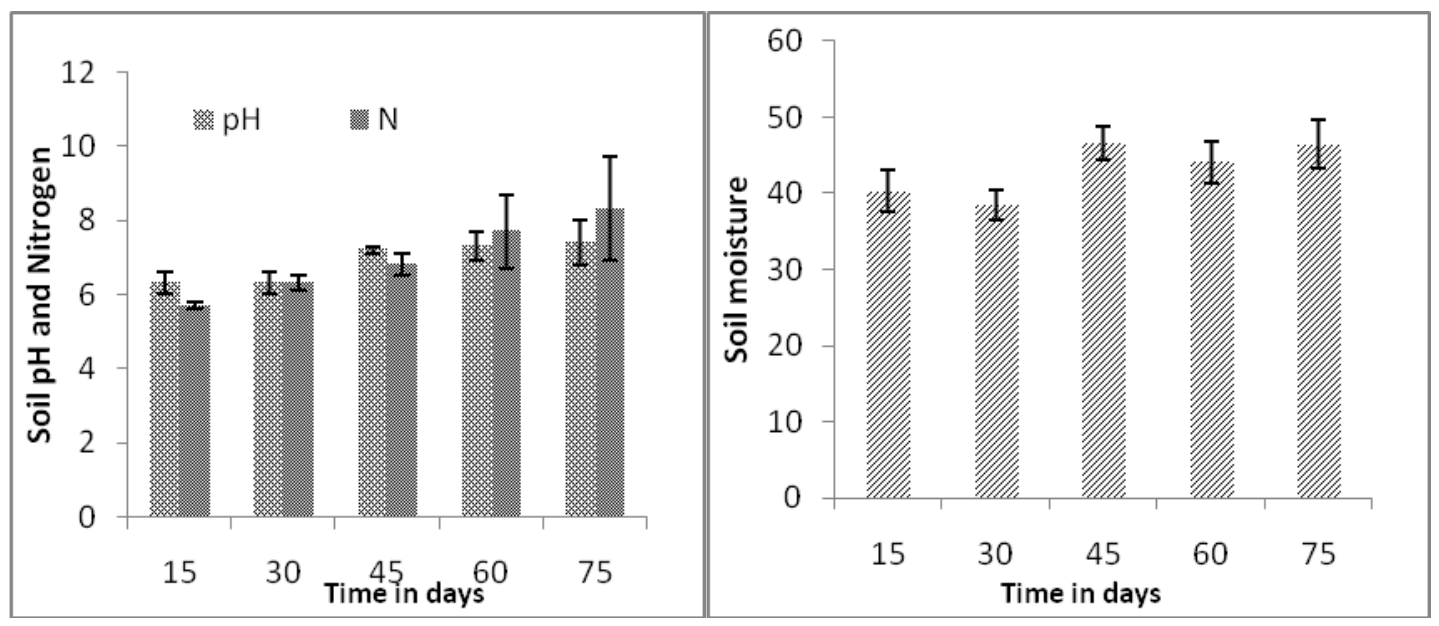

Fig.3 and 4 Soil phosphorous during development of mycorrhizal soil and soil organic carbon during development of mycorrhizal soil

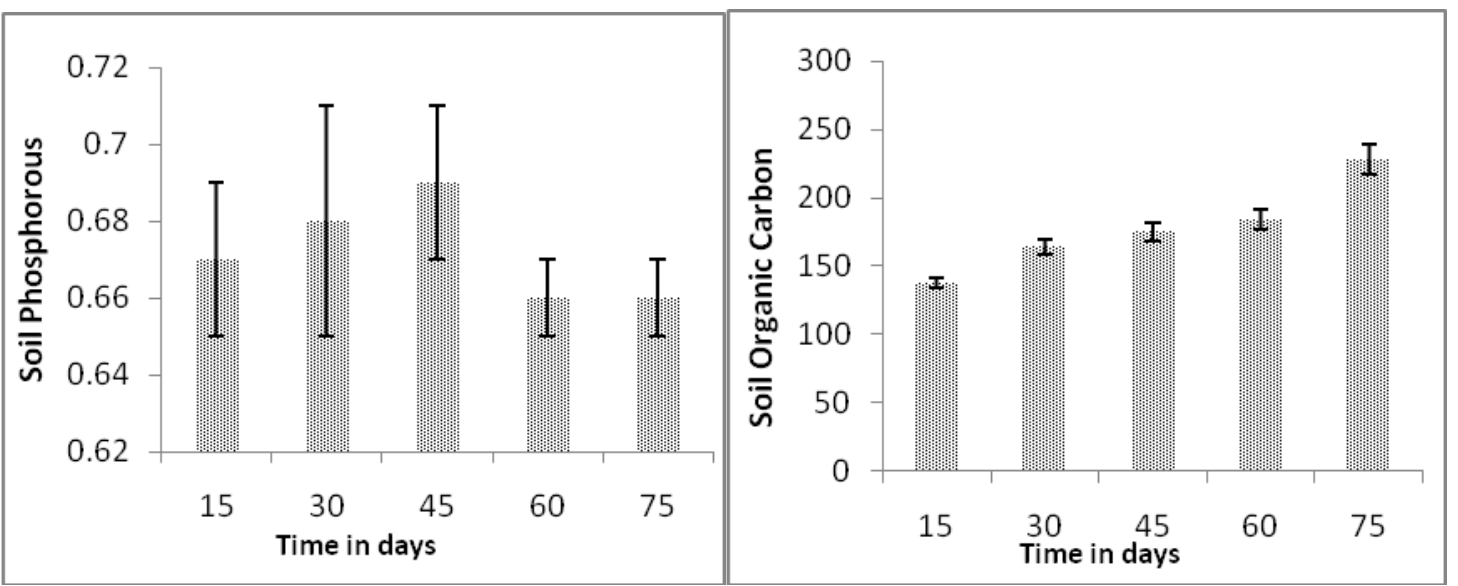


Table.2

\begin{tabular}{lccccc} 
& Phosphorous & $\mathbf{p H}$ & Organic Carbon & Moisture & Nitrogen \\
\hline Root Colonization & -.332 & $.890^{*}$ & $.942^{*}$ & .736 & $.963^{*}$ \\
Spore Count & -.304 & .873 & $.924^{*}$ & .709 & $.948^{*}$ \\
Phosphorous & & -.312 & -.441 & -.094 & -.560 \\
pH & & .809 & $.934^{*}$ & $.894^{*}$ \\
Organic Carbon & & & & .697 & $.953^{*}$ \\
Moisture & & & & .725
\end{tabular}

** Correlation is significant at the 0.01 level ( 2 -tailed), ${ }^{*}$ Correlation is significant at the 0.05 level ( 2 -tailed).

Fig.5a and 5b Relationship between root colonization and spore count in mycorrhizal soil (5a) and control soil (5b)

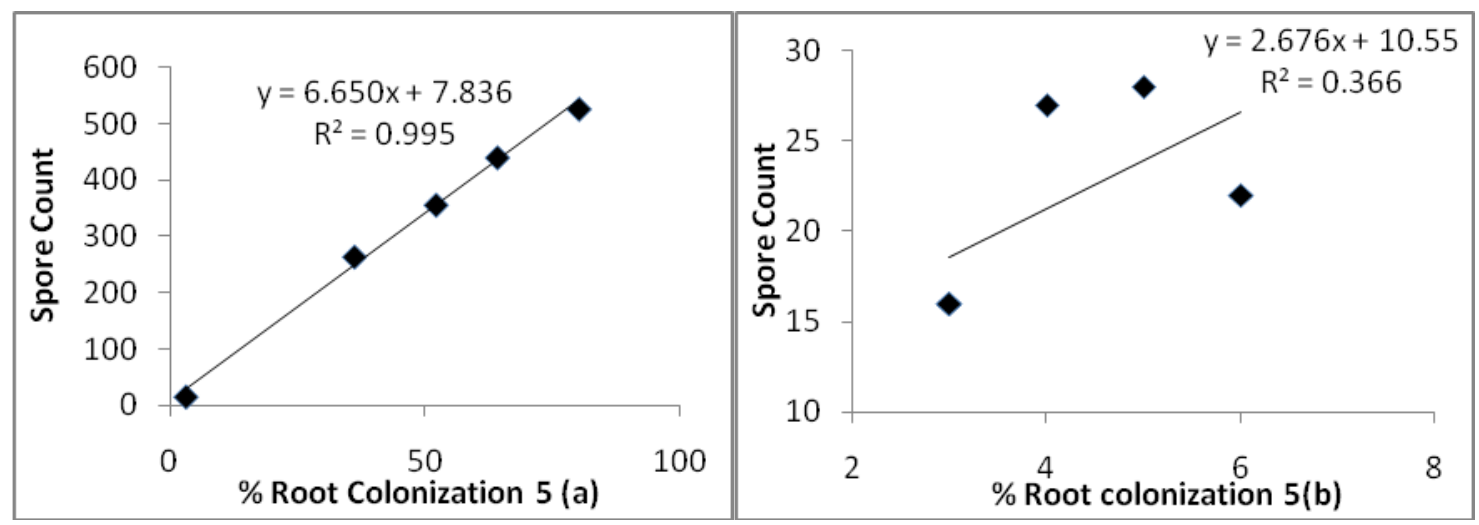

Soil nitrogen positively correlated with spore count and root colonization which corroborates with the findings of Aziz and Habte (1989) who reported that nitrogen stimulates root colonization. The negative correlation was observed between the spore counts and root colonization with phosphorous content, which was not significant (Table 2). Phosphorus had a negative influence on the spore count and root colonization. A negative association between extractable soil phosphates spore number (Syliva and Neal, 1990) and the abundance of VAM colonization (Morita and Konishi, 1989) reported in previous studies. Zerihun et al., (2013) showed a negative correlation between the available $\mathrm{P}$ concentration in soil and root colonization levels. The low soil phosphorous content could be ecologically significant for AMF in uptake of the phosphorous and also where the $\mathrm{p}$ concentration is low the potential of colonization is high. In some cases arbuscular mycorrhizae are reported to take relatively high amount of carbon, while providing little phosphorous. While organic carbon, showed a significant correlation between spore count and root colonization (Table 2). The soil organic carbon was found to increase from $138 \pm 3.8$ to $228 \pm 10.62$ (Fig. 4).

Root colonization and spore count during development of mycorrhizal soil was found to be increasing with the increasing time period than that of the control soil. Initially at an interval of 15 days root colonization and spore count was very less both for the control soil and mycorrhizal soil. In the mycorrhizal soil, spore count showed a highly significant correlation $(\mathrm{P}<0.001)$ with root colonization (Fig. 5a) while variation found in correlation of spore count and root colonization of control soil. The control soil showed insignificant positive $(\mathrm{P}>0.05)$ correlation between spore count and root colonization (Fig. 5b). Khalil et al., (1992) reported that subsequent sporulation and root colonization may differ depending on the edaphic factors, on the host, fungal species. Increase in root colonization and spore 
count was observed at an interval of 30 days which was found to be $36 \%$ with spore count 264/100gm of developed soil and 3\% root colonization with spore count 16/100gm of control soil, which increased from $264 / 100 \mathrm{gms}$ to $356 / 100 \mathrm{gms}$ spore with $52 \%$ root colonization at 45 days in mycorrhizal soil and spore count $16 / 100 \mathrm{gms}$ to $27 / 100 \mathrm{gms}$ with $4 \%$ root colonization for control soil (Figure 5).

At an interval of 60 days spore count increased to $440 / 100 \mathrm{gms}$ with $64 \%$ root colonization in mycorrhizal soil and control soil showed increase in root colonization from $4 \%$ to $5 \%$ with spore count $28 / 100 \mathrm{gms}$ of soil. At the end of the experiment i.e. 75 days spore count was found to be 526/100gms of soil with $80 \%$ of root colonization, when compared with control only $6 \%$ root colonization was observed with spore count 22/100gms of soil (Fig. 5a and b). It is clearly evident from the results that root colonization showed at strong positive correlation with spore count in mycorrhizal soil and it is assumed that increase in root colonization resulted increase in spore count during development of mycorrhizal soil as compared to control soil which showed weak positive correlation. However, some researchers reported that no significant correlation between spore density and VAM colonization (Li et al., 2007). Generally, the spore availability influences AMF colonization (Muthukumar et al., 2003).

\section{Conclusion}

Under controlled greenhouse condition the potential of sorghum bicolor for development of soil based mycorrhizal inoculum was investigated. It was found that Sorghum bicolor used for the development mycorrhizal soil had a significant increase in the nutrient content of soil as compared to that of alluvial soil. This also had a significant impact on root colonization and spore count, where root colonization has resulted increase in the nutrient contents such as organic carbon and Nitrogen while not much difference in phosphorous content of soil was found. Negative correlation between the available phosphorous and root colonization was observed, so the adaptation of AM to the low phosphorous soil was confirmed. The development of mycorrhizal soil using sorghum improved soil physico-chemical parameters all the factors responsible for rhizosphere bioremediation of organic compounds. Thus a soil based mycorrhizal inoculum developed in the laboratory condition can be used further for effective rhizosphere bioremediation of organic pollutants.

\section{References}

Kirk, P. M.; Cannon, P. F.; David, J. C. and Stalpers, J. (2001). Ainsworth and Bisby's Dictionary of the Fungi (9th edn.). Wallingford, UK: CAB International

Caravaca F, Alguacil MM, Barea JM and Roldan A (2005) Survival of inocula and native AM fungi species associated with shrubs in degraded Mediterranean ecosystem. Soil Biology and Biochemistry 37: 227-233.

Azcón R., Ambrosano E., Charest C. (2003): Nutrient acquisition in mycorrhizal lettuce plants under different phosphorus and nitrogen concentration. Plant Science, 165: 1137-1145

M.F. Allen, W. Swenson, J.I. Ouerejeta, L.M. EgertonWarburton and K.K. Treseder, Ecology of mycorrhizae: A conceptual framework for complex interactions among plants and fungi, Annual Review of Phytopathology, 41(2003), 271-303.

Khan AG, 2006. Mycorrhizoremediation - an enhanced form of phytoremediation. Journal of Zhejiang University Science B 7(7): 503-514

Schoor JL, 1997. Phytoremediation. Technical Evaluation Report for Ground-Water Remediation Technologies Analysis Center, Pittsburgh

Huang H, Zhang S, Chen B, Wu N, Shan X, Christy P, 2006. Uptake of Atrazine and Cadmium from Soil by Maize (Zea mays L.) in Association with the Arbuscular Mycorrhizal Fungus Glomus Etunicatum. Journal of Agricultural and Food Chemistry 54: 9377-9382.

Sainz MJ, Gonza'Lez-Penalta B, VilariñOA, 2006. Effects of hexachlorocyclohexane on rhizosphere fungal propagules and root colonization by arbuscular mycorrhizal fungi in Plantago lanceolata. European Journal of Soil Science 57: 83-90.

Volante A, Lingua G, Patrizia esaro, Cresta A, Puppo M, Ariati L, Berta G, 2005. Influence of three species of arbuscular mycorrhizal fungi on the persistence of aromatic hydrocarbons in contaminated substrates. Mycorrhiza 16: 43- 50.

JACKSON, M.L., 1973, Soil Chemical Analysis, Prentice Hall of India Pvt. Ltd., New Delhi, p. 3856.

Bernmer,J.M., and C.S. Mulvaney.1982.Nitrogen-total.p 595-624. In A.L.Page et al.,(ed.).Methods of soil analysis.Part $2.2^{\text {nd }}$ ed.Argon.Monogr.9. ASA and SSSA. Madison.WI.

Dick, W.A., and M.A. Tabatabai. 1977. An alkaline oxidation method for determination of total 
phosphorus in soils. Soil Sci. Soc. Am. J. 41:511514.

Gerdemann JW. and Nicholson TH, 1963. Spores of mycorrhizal endogone species extracted from soil by wet sieving and decanting. Transactions of the British Mycological Society 46: 235-244.

Phillips JM. and Hayman DS, 1970. Improved procedure for clearing roots and staining parasitic and vesicular arbuscular mycorrhizal fungus for rapid assessment of infection. Transactions of the British Myological Society 55: 158-161

ZAR,]. H. 1984. Biostatistical Analysis. New Jersey: Englewood Cliffs, Prentice-Hall Inc.

Redhead JF (1975) Endotrophic mycorrhizal in Nigeria: some aspects of the ecology of the endotrophic mycorrhizal association of Khaya gandiflora C.D.C. In: Ectomycorrhizas. F.E.Sanders; B.Mosse and P.B Tinker (eds). New York Academic Press, p.447-460

Robson AD, Abott LK (1989) The effect of soil acidity on microbial activity in soils. In: Soil acidity and plant growth. A.D. Robson. (ed). Sydney Academic Press,p 139-165.

MOOSE, B., D. B. STRIBLEYand F. LE TACON. 1981. Ecology of mycorrhizae and mycorrhizal fungi. Adv. Microb. Ecol. 5: 137-210.

Aziz T, Habte M (1989) Influence of inorganic $N$ on mycorrhizal activity nodulation and growth of Leucanea leucocephala in an oxisol subjected to stimulated erosion. Commun. Soil Sci Plant Anal 20:239-251.

Morita A, Khonishi S(1989) Relationship between Vesicular Arbuscular mycorrhizal infection and soil phosphorous concentration in tea fields. Soil Sci. Plan. Nutr 35:139-143.

Sylvia DM, Neal LH(1990) Nitrogen affects the phosphorous response of VA mycorrhizal. New Phytol 115:303-310.

Zerihun Belay, Mauritz Vestberg and Fassil Assefa (2013) Diversity and abundance of arbuscular mycorrhizal fungi associated with acacia trees from different land use systems in Ethiopia. Vol. 7(48), pp. 5503-5515

Khalil S, Loynachan TE, Mc Nabb HS(1992) colonization of soyabean by mycorrhizal fungi and spore population in Iowa soil. Agron J 84:832-836

Li, L.F., Zhang, Y. and Zhao, Z.W. (2007b). Arbuscular mycorrhizal colonization and spore density across different land-use types in a hot and arid ecosystem, Southwest China. Journal of Plant Nutrition and Soil Science 170: 419-425.

Muthukumar, T., Sha, L.Q., Yang, X.D., Cao, M., Tang, J.W. and Zheng, Z. (2003a). Mycorrhiza of plants in different vegetation types in tropical ecosystems of Xishuangbanna, southwest China. Mycorrhiza 13: 289-297.

How to cite this article:

Jyoti Fulekar, Bhawana Pathak and Fulekar, M.H. 2017. Development of Mycorrhizosphere Using Sorghum bicolor for Rhizosphere Biormediation. Int.J.Curr.Res.Aca.Rev. 5(6), 42-48.

doi: https://doi.org/10.20546/ijcrar.2017.506.006 